\title{
Activity and Immune Correlates of a Programmed Death-1 Blockade Antibody in the treatment of Refractory Solid Tumors
}

\author{
Chang Jiang ${ }^{1,2,3 *}$, Xiuyu Cai ${ }^{1,2,3 *}$, Hongxia Zhang ${ }^{2,3}$, Xiaojun Xia ${ }^{2,3}$, Bei Zhang1,2,3, Liangping Xia ${ }^{1,2,3 凶}$ \\ 1. VIP Region, Sun Yat-Sen University Cancer Center, Guangzhou, Guangdong, 510060, R.P. China; \\ 2. State Key Laboratory of Oncology in South China, Sun Yat-Sen University Cancer Center, Guangzhou, Guangdong, 510060, R.P. China; \\ 3. Collaborative Innovation Center for Cancer Medicine, Guangzhou, Guangdong, 510060, R.P. China. \\ * contributed equally to this paper \\ $\square$ Corresponding author: Liangping Xia, E-mail: xialp@sysucc.org.cn; Fax: +86 20-87343392; Tel: +86 20-87343107; Mobile: +86-13926410608.
}

(c) Ivyspring International Publisher. This is an open access article distributed under the terms of the Creative Commons Attribution (CC BY-NC) license (https://creativecommons.org/licenses/by-nc/4.0/). See http://ivyspring.com/terms for full terms and conditions.

Received: 2017.06.10; Accepted: 2017.10.10; Published: 2018.01.01

\begin{abstract}
Background: Blockade of programmed death 1 (PD-1), an inhibitory $\mathrm{T}$ lymphocyte receptor, is associated with immune system enhancement and tumor remission in various tumors. We assessed the anti-tumor activity and immune correlates of cancer patients treated with an anti-PD-1 antibody.

Patients and Methods: Twelve patients with advanced metastatic tumors were treated with anti-PD-1 antibody. Responses were assessed after a 12-week treatment regimen. Biochemical and immunological indexes were measured before each cycle.

Results: Among the 12 patients, 3 patients showed partial response while 6 patients had stable disease (objective response rate: $3 / 12,25 \%$; disease control rate: $9 / 12,75 \%$ ). During immunotherapy, the proportion of circulating CD3+ $\mathrm{T}$ lymphocytes remained stable, with decreasing trends of $\mathrm{CD} 3^{+} \mathrm{CD} 4^{+} \mathrm{T}$ helper cell and increase in $\mathrm{CD}^{+}{ }^{+} \mathrm{CD}^{+} \mathrm{T}$ memory cells, in patients with stable disease. Additionally, an increase in serum lactate dehydrogenase levels seemed to correlate with tumor progression.

Conclusions: An anti-PD-1 antibody produced objective responses in approximately $25 \%$ patients with various solid tumors, demonstrating that it could improve the immune system in vivo.
\end{abstract}

Key words: programmed death 1 antibody, refractory solid tumors, clinical activity, lymphocyte.

\section{Introduction}

A greater understanding of the underlying molecular mechanisms of immune system regulation is leading to a gradual recognition of the role of local immune suppression, immune tolerance, and immune escape in the tumor microenvironment. The concept of releasing the "brakes" on anti-cancer immunity is a breakthrough in cancer treatment [1]. Excluding the encouraging efficacy of passive immunotherapies such as monoclonal antibodies [2], $\mathrm{T}$ cell-based immunotherapies are usually less effective [3]. The underlying mechanism include the tumor cells developing various resistance mechanisms, such as restraining the immune response via "immune checkpoints" [4]. The first clinically validated checkpoint target was cytotoxic $\mathrm{T}$ lymphocyteassociated antigen 4 (CTLA-4), a negative regulator of T-cell activation [5]. The antagonist anti-CTLA-4 mediates tumor regression, most notably in patients with melanoma [6], and has been approved for the treatment of stage IV melanoma on the basis of its promising efficacy [7]. In clinical practice, antibodies blocking negative immunological checkpoints have demonstrated antitumor activity in various advanced malignancies [8].

Programmed death 1 (PD-1) protein is a key immunosuppressive checkpoint receptor expressed in activated T cells [9]. PD-L1 is the primary PD-1 ligand that is up-regulated in many tumor $[10,11]$ and 
stromal cells of the microenvironment [12]. The PD-1/PD-L1 interaction can inhibit cytokine production and negatively affect the functioning of tumor-infiltrating $\mathrm{CD}^{+}$and $\mathrm{CD}^{+}{ }^{+} \mathrm{T}$ cells $[13,14]$. Blocking the PD-1/PD-L1 interaction has been shown to augment $T$ cell responses in preclinical models [15]. Agents targeting the PD-1/PD-L1 axis have achieved amazing improvements in multiple tumors, including melanomas [16], non-small-cell lung cancer [17], Hodgkin's lymphoma [18], renal-cell carcinoma [19], and bladder cancer [20]. Several associated clinical trials are in progress [21]. However, though an emerging therapy, the potential biomarkers for monitoring clinical response and outcome remain elusive for this treatment modality. Huang et al. have recently reported that the ratio of T-exhausted cell $\left(\mathrm{T}_{\mathrm{ex}}, \mathrm{Ki} 67^{+} \mathrm{CD} 8^{+} \mathrm{T}\right.$ cell $)$ invigoration to tumor burden is associated with anti-PD-1 activity, but the predictive value of such a ratio remains to be validated in different cancer types [22]. Therefore, it is imperative to ascertain the activity of anti-PD-1 in varied cancers and translate the insights into efficient drugs and effective biomarkers for daily clinical practice. In this paper, we present the clinical activity and the immune correlates of anti-PD-1 antibody in patients with advanced cancers.

\section{Materials and Methods}

\section{Patients and treatment}

We retrospectively analyzed 12 patients with treatment-refractory advanced/ metastatic solid tumors at the Sun Yat-Sen University Cancer Center, from January 2015 to July 2016. Patients were treated with anti-PD-1 antibodies, either pembrolizumab or nivolumab, for a minimum of 12 weeks. Other inclusion criteria included an age of minimum 18 years; an Eastern Cooperative Oncology Group performance status of 2 or less [23]; measurable disease as defined by response evaluation criteria in solid tumors (RECIST, version 1.1) [24]; presence of adequate hematologic, cardiac, hepatic, and renal function; and a history of standard systemic treatment regimens. Patients with treated stable primary or metastatic brain lesions for a minimum of 8 weeks were eligible. Patients with the presence of any current systemic infections, a history of human immunodeficiency virus infection, or active hepatitis $\mathrm{B}$ or $\mathrm{C}$ virus infection, or a history of autoimmune disease with systemic glucocorticoid or immunosuppressive therapy were excluded. Patients with a history of prior treatment with T-cell modulating antibodies (including anti-PD-1, anti-PD-L1, and anti-CTLA-4) were also excluded from the study. Patients who lacked a pathological diagnosis or a complete medical history, lost to follow-up, had two or more kinds of tumors asynchronously or synchronously were excluded. Patients with merely non-measurable lesions or active brain metastatic lesions were excluded from the study.

Patients received either pembrolizumab (2 $\mathrm{mg} / \mathrm{kg}$, every 3 weeks) or nivolumab ( $3 \mathrm{mg} / \mathrm{kg}$, every 2 weeks) as single agent or combined therapy until disease progression or report of unacceptable toxicity.

Each patient was followed up through telephone or the recent outpatient records. In addition, complete patient records were kept in our electronic information system.

\section{Tumor burden and response assessment}

Total tumor burden was defined as the sum of the long axis of all measurable lesions $(\geq 10 \mathrm{~mm}$ in the longest diameter) on the imaging reports before administration of PD-1 antibody therapy.

Responses were evaluated by computed tomography or magnetic resonance imaging at week 6 . The categories of response were complete response, partial response (PR), stable disease (SD) or progressive disease (PD) based on immune-related response criteria (irRECIST) using unidimensional measurements, at the week-6 time point [25]. Serum biochemical index, tumor marker levels, and peripheral blood lymphocyte (PBL) phenotypes were assessed before each cycle of anti-PD-1 antibody administration.

\section{Flow cytometry}

We collected whole blood samples of 6 patients before PD-1 antibody treatment at indicated cycles, 1-2 (weeks 3-6). Peripheral blood mononuclear cell (PBMC) samples were isolated by density-gradient centrifugation using lymphoprep (MD pacific, Tianjin, China) and cryopreserved. Before conducting flow cytometry, the PBMC samples were thawed, washed twice with phosphate buffer saline and incubated with antibodies for surface markers including CD3 PerCP-cy5.5 (eBioscience), CD4 APC-eFlour780 (eBioscience), CD8-FITC (eBioscience), and PD1-APC (eBioscience), followed by staining, for intracellular marker, with Ki67 (Biolegend). The mixture of surface marker antibodies were incubated with the PBMC samples for $30 \mathrm{~min}$ at room temperature in the dark. Permeabilization was performed using the FOXP3/Transcription Factor Staining Buffer Set (eBioscience). Stained cells were suspended in an appropriate volume of flow cytometry staining buffer until data acquisition. A BD Bioscience LSR Fortessa X-20 instrument was used to 
acquire data of the stained samples, which was further analyzed using the FlowJo software.

\section{Human Rights}

The protocol of our study was approved by the Ethics Committee of the Sun Yat-Sen University Cancer Center and complied with the International Ethical Guidelines for Biomedical Research Involving Human Subjects, Good Clinical Practice guidelines, the Declaration of Helsinki, and local laws. Written informed consent was obtained from each patient.

\section{Results}

\section{Patients and Treatments}

A total of 12 patients with treatment-refractory advanced/ metastatic tumors were enrolled in our study. These included 3 patients with non-small cell lung cancer (NSCLC), 1 with small cell lung cancer, 1 with nasopharynx cancer, 1 with laryngopharynx cancer, 1 with gastric cancer, 1 with gastrointestinal stromal tumor of the duodenum, 1 with hepatic squamous cancer, 1 with bladder cancer, 1 with glioma, and 1 with metastatic non-small cell carcinoma (with unknown primary lesion) (Table 1).

Among the patients, 10 were administered pembrolizumab and 2 received nivolumab. Eight patients accepted the PD-1 antibody therapy in the first-line setting, while 4 in the second-line setting or later. There were 2 patients who continued the PD-1 antibody therapy after showing the first disease progression. Patients received an average of 10 cycles of PD-1 antibodies (range 4-27 cycles). Ten patients received PD-1 antibodies as combined therapy and 2 patients as monotherapy (Table 2). Until date, 6 patients are still continuing the PD-1 antibodies therapy, while the other 6 have stopped the PD-1 treatment, including 5 patients with tumor progression and 1 with serious therapy-related rashes.

\section{Clinical Activity}

Clinical activity was assessed via radiographic and serum tumor marker levels. According to the RECIST 1.1 criteria, PR and PD represent a minimum decrease of $30 \%$ and $20 \%$, respectively, in the sum of diameters of target lesions, taking the smallest sum, or the appearance of one or more new lesions as reference. SD represents neither sufficient shrinkage to qualify for PR nor sufficient increase to qualify for PD. The positive response was observed in 9 patients, and $\mathrm{PR}$ in 3 (objective response rate: 3/12, 25\%; disease control rate: 9/12, 75\%; Table 2, Figure 1A). The other 3 patients, with NSCLC, gastric cancer, and hepatic cancer, had disease progression. The variation tendency of elevated baseline tumor biomarkers was in concurrence with the radiographic responses (Figure 1B). All the patients who showed a response exhibited decreased or stable tumor marker levels while patients with tumor progression had remarkably increased tumor marker levels.

\section{Peripheral blood lymphocyte change}

We collected the baseline proportion of peripheral blood lymphocyte before administration of PD-1 antibodies treatment (Table 3). After the PD-1 treatment, the proportion of total CD3 + T lymphocyte did not significantly alter. Despite the varied responses, the proportion of the $\mathrm{CD}^{+} \mathrm{CD}^{+} \mathrm{T}$ lymphocyte subset seemed to decline while that of $\mathrm{CD}^{+}{ }^{+} \mathrm{CD} 8^{+} \mathrm{T}$ lymphocyte subset seemed to increase, in patients with stable disease. These trends were not observed for natural killer $\left(\mathrm{CD} 3-\mathrm{CD} 16^{+} \mathrm{CD} 56^{+}\right)$cells (Figure 2).

\section{T-cell reinvigoration and tumor burden}

Pre- and post-immunotherapy, we tested changes in Ki67 expression and estimated tumor burden, in peripheral blood mononuclear cell (PBMC) samples of the patients. In our study, we failed to find a correlation between $\mathrm{Ki} 67^{+} \mathrm{CD} 8 \mathrm{~T}$ cell reinvigoration and therapy efficacy in 6 patients (Figure 3).

Table 1. Clinical Characteristics of Patients

\begin{tabular}{lllll}
\hline Patient number & Sex & Age (years) & Diagnosis & Pathological type \\
\hline 1 & Male & 61 & NSCLC & adenocarcinoma \\
2 & Male & 44 & Laryngopharynx cancer & unknown ${ }^{1}$ \\
3 & Male & 51 & Bladder cancer & urothelium carcinoma \\
4 & Male & 71 & SCLC & small cell carcinoma \\
5 & Male & 61 & Metastatic cancer & non-small cell carcinoma \\
6 & Female & 53 & GIST of duodenum & GIST \\
7 & Male & 52 & NPC & squamous carcinoma \\
8 & Male & 53 & Glioma & glioblastoma \\
9 & Male & 79 & NSCLC & non-small cell carcinoma \\
10 & Male & 49 & Hepatic cancer & squamous carcinoma \\
11 & Male & 56 & NSCLC & squamous carcinoma \\
12 & Male & 71 & Gastric cancer & adenocarcinoma \\
\hline
\end{tabular}

1: the pathological diagnosis lacks the details about the type; 2: patients with recurrent glioblastoma (WHO IV). Abbreviations: NSCLC, non-small cell lung cancer; SCLC, small cell lung cancer; GIST, gastrointestinal stromal tumor; NPC, nasopharynx cancer. 


\section{Changes in serum biochemical index}

In our study, $50 \%$ of the patients $(6 / 12)$ had increased baseline LDH levels. As the sample size was too small to analyze the survival, we evaluated the correlation between change in $\mathrm{LDH}$ levels and tumor response (Figure 4). Patients with disease progression appeared to have a trend of increasing LDH levels during the treatment period while patients with tumor remission or stable disease had steady or reduced LDH levels.

\section{Discussion}

As a promising anticancer strategy, the efficacy data of anti PD-1/ PD-L1 antibodies mostly derived from the clinical trial. We introduced the activity and immune correlates in our clinical practice, focusing on Chinese patients. Our data showed that nearly 1 in 4 patients, treated with PD-1 antibodies, showed objective responses in diverse refractory solid tumors. One possible reason for the promising effect could be that we eliminated the probable, rapidly progressing patients who underwent anti PD-1 therapy for less than 12 weeks. The robustness of disease control in patients on immunotherapy was also noteworthy across various cancers types. A new concept of basket trials offer an innovative approach to patients according to the genetic mutations discovered through specialized molecular testing other than disease type. There were 4 patients (Patient number: $1,3,6$, and 8) with enduring response durations of 12 months or longer. This observation is similar to that observed in the study by Topalian et al., despite variations in the cancer types evaluated in this study [4]. Some studies had also presented the clinical

A

Radiographic response
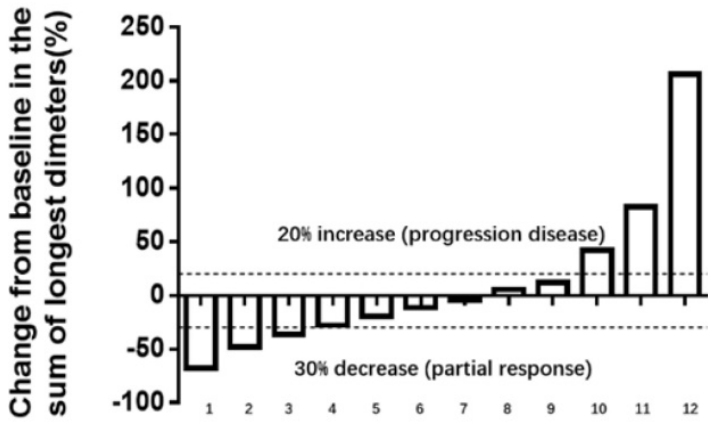

Patient number activity of anti PD-1/ PD-L1 antibodies in various refractory tumors $[26,27]$.

Table 2. Treatment Characteristics and Clinical Response to Therapy

\begin{tabular}{|c|c|c|c|c|c|}
\hline $\begin{array}{l}\text { Patient } \\
\text { number }\end{array}$ & $\begin{array}{l}\text { Immunotherapy } \\
\text { agent }\end{array}$ & $\begin{array}{l}\text { Cycles } \\
\text { applied }\end{array}$ & $\begin{array}{l}\text { Treatment } \\
\text { line }\end{array}$ & $\begin{array}{l}\text { Combined } \\
\text { therapy }\end{array}$ & $\begin{array}{l}\text { Best response to } \\
\text { immunotherapy }\end{array}$ \\
\hline 1 & Pembrolizumab & 11 & $1^{\text {st }}$ & Yes & PR \\
\hline 2 & Pembrolizumab & 8 & $1^{\text {st }}$ & Yes & PR \\
\hline 3 & Pembrolizumab & 14 & $1^{\text {st }}$ & Yes & PR \\
\hline 4 & Nivolumab & 8 & $1^{\text {st }}$ & Yes & SD \\
\hline 5 & Pembrolizumab & 9 & $2^{\text {nd }}, 3^{\text {rd }}$ & Yes & SD \\
\hline 6 & Pembrolizumab & 14 & $1^{\text {st }}$ & No & SD \\
\hline 7 & Pembrolizumab & 8 & Beyond 2nd & Yes & SD \\
\hline 8 & Pembrolizumab & 27 & $1^{\text {st }}, 2^{\text {nd }}$ & Yes & SD \\
\hline 9 & Pembrolizumab & 8 & $1^{\text {st }}$ & No & SD \\
\hline 10 & Pembrolizumab & 5 & $1^{\text {st }}$ & No & PD \\
\hline 11 & Nivolumab & 9 & $2^{\text {nd }}$ & Yes & PD \\
\hline 12 & Pembrolizumab & 4 & $3^{\text {rd }}$ & No & PD \\
\hline
\end{tabular}

Table 3. Baseline Proportion of Peripheral Blood Lymphocytes

\begin{tabular}{lllll}
\hline $\begin{array}{l}\text { Patient } \\
\text { number }\end{array}$ & $\begin{array}{l}\text { Baseline } \mathrm{CD}^{+} \mathrm{T} \\
\text { lymphocyte } \\
\text { proportion }(\%)\end{array}$ & $\begin{array}{l}\text { Baseline } \\
\mathrm{CD} 3^{+} \mathrm{CD}^{+} \mathrm{T} \\
\text { lymphocyte } \\
\text { proportion }(\%)\end{array}$ & $\begin{array}{l}\text { Baseline } \\
\mathrm{CD} 3^{+} \mathrm{CD} 8^{+} \mathrm{T} \\
\text { lymphocyte } \\
\text { proportion } \\
(\%)\end{array}$ & $\begin{array}{l}\text { Baseline } \\
\mathrm{CD} 3-\mathrm{CD} 16^{+} \mathrm{CD} 56^{+} \\
\text {natural killer cell } \\
\text { proportion (\%) }\end{array}$ \\
\hline 1 & 70.8 & 17.2 & 33.8 & 17.9 \\
2 & 68.5 & 23.5 & 33.9 & 23.3 \\
3 & 82.4 & 41.7 & 20.1 & 5.2 \\
4 & 76.1 & 49.0 & 22.8 & 13.3 \\
5 & 56 & 6.5 & 45.4 & 40.8 \\
6 & 81.1 & 45.1 & 27.9 & 15.8 \\
7 & 62.7 & 12.9 & 47.0 & 28.1 \\
8 & 60.2 & 27.0 & 26.2 & 32.5 \\
9 & 54.3 & 34.8 & 17.3 & 29.7 \\
10 & 91.6 & 20.4 & 61.8 & 5.9 \\
11 & 75.9 & 48.9 & 21.5 & 15.2 \\
12 & 66.5 & 33.7 & 26.1 & 31.0 \\
\hline
\end{tabular}

Reference range: $\mathrm{CD}^{+} \mathrm{T}$ lymphocyte, $59.1 \%-74.9 \%$; $\mathrm{CD}^{+}{ }^{+} \mathrm{CD} 4+{ }^{+} \mathrm{T}$ lymphocyte, $26.6 \%-40.4 \%$; CD3 ${ }^{+} \mathrm{CD} 8+$ T lymphocyte, $23.6 \%-35.8 \%$; CD3-CD $16+\mathrm{CD} 56^{+}$natural killer cell, $12.2 \%-24.8 \%$.

B

Biochemical response

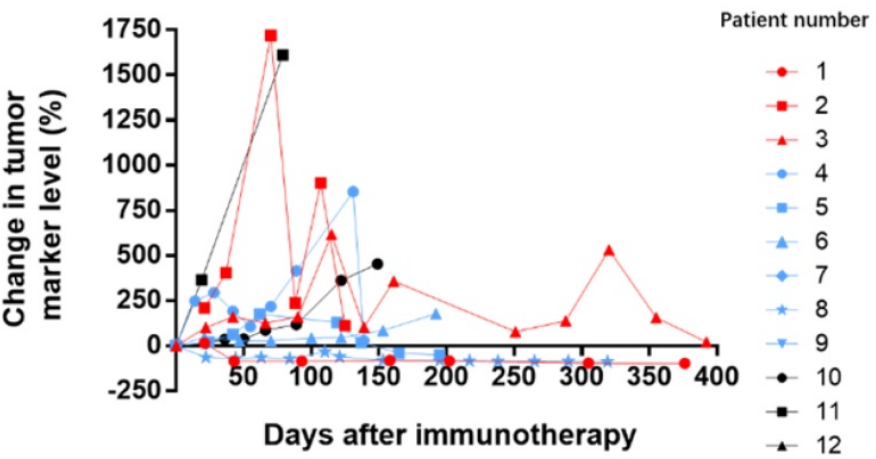

Figure 1. Tumor responses on treatment with PD-1 antibodies. A: Radiographic responses evaluated based on response evaluation criteria in solid tumors (RECIST 1.1). The values shown are the largest percentage change in the sum of longest diameters from the baseline measurements of each measurable tumor. Each bar represents one patient. B: Serum levels of tumor biomarkers were measured at the start of each treatment cycle, and the values represent percentage changes from baseline. Each line represents 1 patient; patients with high baseline levels for tumor markers were included. Cytokeratin-19 fragments (CYFRA21-1) was used as the biomarker for 3 patients with non-small cell lung cancer, 1 with gastric cancer, and 1 with bladder cancer. Neuronal specific enolase (NSE) was used as a marker for 1 patient with small cell lung cancer. Carbohydrate antigens 125 (CA125) was used as a marker for 1 patient with a gastrointestinal stromal tumor. CA72-4 was used for 1 patient with laryngopharynx cancer. Alpha-fetal protein (AFP) was used as a marker for 1 patient with metastatic cancer. The other 3 patients had normal biomarker profiles during the treatment period. 


\section{PBL phenotype change}

A



C

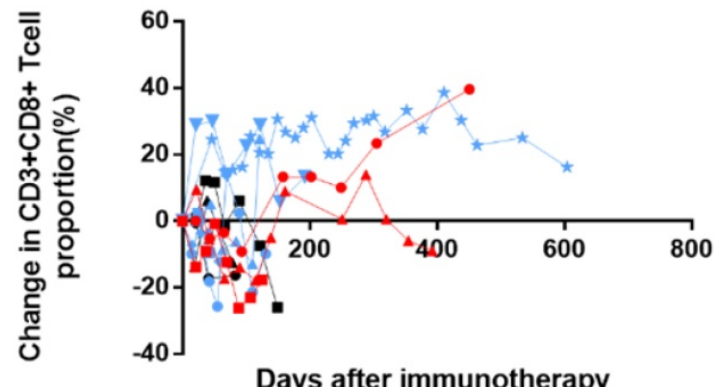

B

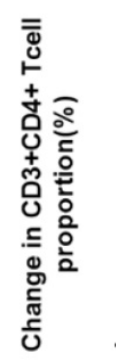

atient number

- 1

$-2$

Days after immunotherapy -2

D



Figure 2. Effects of PD-1 antibodies on peripheral blood lymphocyte proportion. $A$ and $D$ : During immunotherapy, the proportion of total CD3+ $T$ lymphocyte and CD3-CD16+CD56+ natural killer cells remained unchanged. B and C: In the subset analysis, the proportion of CD3+CD4+ $T$ lymphocytes seem to show a downward trend, while the proportion of $C D 3^{+} C D 8^{+}-T$ lymphocytes show an upward trend in patients with stable disease.

A

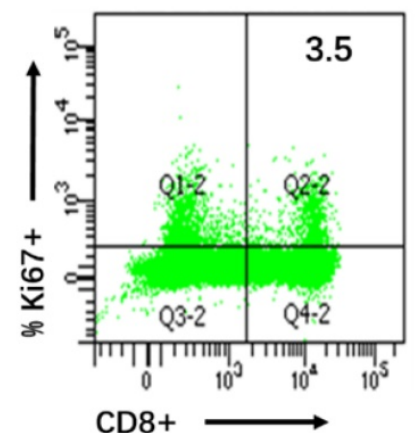

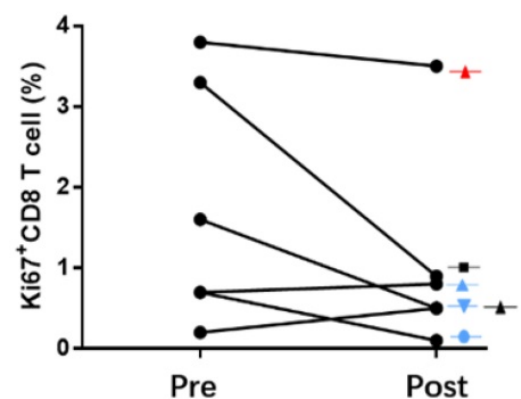

C



Figure 3. Ki67+CD8+ $\mathbf{T}$ cell reinvigoration and therapy efficacy. A: Example of Ki67 expression in peripheral blood CD8 ${ }^{+} T$ cells; $B$ and $C:$ In the samples of 6 patients, there were no trends of correlation among therapy response, ratio of $\mathrm{Ki} 67^{+} \mathrm{CD} 8+\mathrm{T}$ cell reinvigoration to tumor burden, pre- or post- immunotherapy.

\section{Serum LDH level change}

A

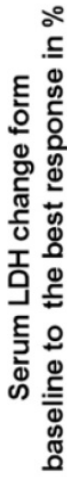

B



Days after immunotherapy

Figure 4. Association between changes in serum LDH levels and tumor response. During the treatment period, a decreasing trend was observed in the mean LDH levels of patients with remission and stable disease, while an increasing trend was noted in patients with progression 
As a primary ligand of PD-1, PD-L1 shows inducible expression in the tumor and stromal microenvironment in response to inflammatory or immunological stimulation [12, 28]. Thus, the potential mechanism of tumor immune escape implies that inhibition of the PD-1/PD-L1 interaction might have a synergistic effect, when combined with other therapies, by enhancing the anti-tumor immune response [19, 29]. Such immune responses could become sustaining immunological memory, and produce persistent tumor control [19]. Longer follow up will confirm whether patients benefit continually from checkpoint blockade.

Tumors have the ability to maintain an immunosuppressive situation in the host [30]. The PD-1/PD-L1 axis plays a negative regulatory role in T lymphocyte activation. This enhancement of anti-cancer immunity could be the theoretical rationale for blocking PD-1. Tumor infiltrating CD8 ${ }^{+}$ cell density was higher in both the tumor center and invasive margin of the response group [31]. Accumulation of activated $\mathrm{CD}^{+} \mathrm{T}$ lymphocytes within tumors co-expressing high levels of PD-L1 is very likely to respond to PD-1 antibodies [32]. The percentage of NK cells does not change during the course of PD-1 blocking therapy [33]. Our results on peripheral blood lymphocyte subsets were consistent with intratumor lymphocyte changes.

The lack of a universal predictive biomarker to identify candidate patients is a challenge for PD-1 antibody treatment regimens. The most well-studied biomarker is the expression of PD-L1. Patients with increased PD-L1 expression have remarkably higher response rates to PD-1/PD-L1 blockade in multiple tumors [34, 35]. Especially in NSCLC, the PD-1 antibody could be used as first-line treatment in patients showing PD-L1 expression on at least $50 \%$ of the tumor cells [36]. However, some other studies show that the response to PD-1 antibodies is independent of PD-L1 expression [37]. Patients with a mismatch repair deficiency status have been reported to be more responsive to PD-1 antibodies [38]. The Food and Drug administration has approved the first PD-1 antibody for any solid tumor with microsatellite instability-high (MSI-H) or mismatch repair deficiency (dMMR) [39]. The cellular proliferative marker, Ki67, is also considered as a marker for T-cell reinvigoration in vivo $[40,41]$. On PD-1 therapy, the T cell reinvigoration to tumor burden ratio positively correlates with anti-tumor efficacy, and this has been established in mouse models [40] and melanoma patients [22]. Huang et al. [22] have demonstrated that the $\mathrm{T}$ cell reinvigoration positively correlates with tumor burden, and further identified that a higher ratio of $\mathrm{T}$ cell reinvigoration to tumor burden was associated with a better clinical outcome. $\mathrm{T}$ cell reinvigoration/ tumor burden ratio could be a potential predictor of response to PD-1 therapy. However, we did not observe strong $\mathrm{T}$ cell reinvigoration in the peripheral blood of patients after treatment, indicating that such ratio could be cancer type-specific. Further studies are ongoing with an increased sample size.

Serum LDH is a standard and accessible biomarker used in the clinic. Elevated LDH levels has been a well-known marker for monitoring bevacizumab efficacy [42] and prediction of poor outcome in the era of chemotherapy [43]. In terms of immunotherapy, elevated levels of serum lactate dehydrogenase (LDH) has been shown to be related with poorer prognosis, in melanoma patients treated with ipilimumab [44, 45] and anti-PD-1 therapy [46]. Likewise, in the present study, we observed that patients with tumor progression had increased LDH levels during the treatment period. Exploration of the clinical utility of other related candidate biomarkers, such as tumor infiltrating immune cells, interferon- $\gamma$, is also essential [47].

As a novel and expensive therapy, the extensive application of PD-1 blockade is limited in Chinese mainland. So the included cases are fewer. As this is a retrospective, non-randomized study with limited patient sample size, we only provide a mere statistical description of our observations. The above-mentioned limitations prevent us from comparing efficacy with toxicity.

In conclusion, the PD-1 antibody produced objective responses in approximately $25 \%$ of various refractory solid tumors, not resolved during first-line therapy. It could also improve the proportion of $\mathrm{CD}^{+}{ }^{+} \mathrm{CD} 8+\mathrm{T}$ lymphocyte in vivo. The correlation of $\mathrm{T}_{\mathrm{ex}}$ cell phenotype to tumor burden needs to be further estimated in larger number of samples. Moreover, the function of diverse subsets of lymphocyte in the disease state should be explored. In addition, serum LDH should be considered as an accessible, potential predictive marker for anti-PD1 immunotherapy. Furthermore, prospective studies with a large sample size should be conducted to verify the results related to immunological functions and serum markers obtained in the current study.

\section{Acknowledgement}

This study was supported by grants from the Natural Science Foundation of Guangdong, China (2015A030313010), Science and Technology Program of Guangzhou, China (1563000305), and the National Natural Science Foundation of China (81572409). 


\section{Note}

The authenticity of this article has been validated by uploading the key raw data onto the Research Data Deposit public platform (www.researchdata.org.cn), with the approval RDD number as RDDB2017000212.

\section{Competing Interests}

The authors have declared that no competing interest exists.

\section{References}

1. Ribas A. Releasing the Brakes on Cancer Immunotherapy. The New England journal of medicine. 2015; 373: 1490-2.

2. Weiner LM, Surana R, Wang S. Monoclonal antibodies: versatile platforms for cancer immunotherapy. Nature reviews Immunology. 2010; 10: 317-27.

3. Topalian SL, Weiner GJ, Pardoll DM. Cancer immunotherapy comes of age. Journal of clinical oncology : official journal of the American Society of Clinical Oncology. 2011; 29: 4828-36.

4. Topalian SL, Hodi FS, Brahmer JR, Gettinger SN, Smith DC, McDermott DF, et al. Safety, activity, and immune correlates of anti-PD-1 antibody in cancer. The New England journal of medicine. 2012; 366: 2443-54.

5. Pardoll DM. The blockade of immune checkpoints in cancer immunotherapy. Nature reviews Cancer. 2012; 12: 252-64.

6. Phan GQ, Yang JC, Sherry RM, Hwu P, Topalian SL, Schwartzentruber $\mathrm{DJ}$, et al. Cancer regression and autoimmunity induced by cytotoxic $\mathrm{T}$ lymphocyte-associated antigen 4 blockade in patients with metastatic melanoma. Proceedings of the National Academy of Sciences of the United States of America. 2003; 100: 8372-7.

7. Hodi FS, O'Day SJ, McDermott DF, Weber RW, Sosman JA, Haanen JB, et al. Improved survival with ipilimumab in patients with metastatic melanoma. The New England journal of medicine. 2010; 363: 711-23.

8. Postow MA, Callahan MK, Wolchok JD. Immune Checkpoint Blockade in Cancer Therapy. Journal of clinical oncology : official journal of the American Society of Clinical Oncology. 2015; 33: 1974-82.

9. Okazaki T, Honjo T. PD-1 and PD-1 ligands: from discovery to clinical application. International immunology. 2007; 19: 813-24

10. Iwai $Y$, Ishida $M$, Tanaka $Y$, Okazaki T, Honjo T, Minato N. Involvement of PD-L1 on tumor cells in the escape from host immune system and tumor immunotherapy by PD-L1 blockade. Proceedings of the National Academy of Sciences of the United States of America. 2002; 99: 12293-7.

11. Dong H, Strome SE, Salomao DR, Tamura H, Hirano F, Flies DB, et al. Tumor-associated B7-H1 promotes T-cell apoptosis: a potential mechanism of immune evasion. Nature medicine. 2002; 8: 793-800.

12. Curiel TJ, Wei S, Dong H, Alvarez X, Cheng P, Mottram P, et al. Blockade of B7-H1 improves myeloid dendritic cell-mediated antitumor immunity. Nature medicine. 2003; 9: 562-7.

13. Hino R, Kabashima K, Kato Y, Yagi H, Nakamura M, Honjo T, et al. Tumor cell expression of programmed cell death-1 ligand 1 is a prognostic factor for malignant melanoma. Cancer. 2010; 116: 1757-66.

14. Taube JM, Anders RA, Young GD, Xu H, Sharma R, McMiller TL, et al. Colocalization of inflammatory response with B7-h1 expression in human melanocytic lesions supports an adaptive resistance mechanism of immune escape. Science translational medicine. 2012; 4: 127ra37.

15. Blank C, Brown I, Peterson AC, Spiotto M, Iwai Y, Honjo T, et al. PD-L1/B7H-1 inhibits the effector phase of tumor rejection by $\mathrm{T}$ cell receptor (TCR) transgenic CD8+ T cells. Cancer research. 2004; 64: 1140-5.

16. Hamid O, Robert C, Daud A, Hodi FS, Hwu WJ, Kefford R, et al. Safety and tumor responses with lambrolizumab (anti-PD-1) in melanoma. The New England journal of medicine. 2013; 369: 134-44.

17. Muller M, Schouten RD, De Gooijer CJ, Baas P. Pembrolizumab for the treatment of non-small cell lung cancer. Expert review of anticancer therapy. 2017: 1-11.

18. Ansell SM, Lesokhin AM, Borrello I, Halwani A, Scott EC, Gutierrez M, et al. PD-1 blockade with nivolumab in relapsed or refractory Hodgkin's lymphoma. The New England journal of medicine. 2015; 372: 311-9.

19. Brahmer JR, Tykodi SS, Chow LQ, Hwu WJ, Topalian SL, Hwu P, et al. Safety and activity of anti-PD-L1 antibody in patients with advanced cancer. The New England journal of medicine. 2012; 366: 2455-65.

20. Powles T, Eder JP, Fine GD, Braiteh FS, Loriot Y, Cruz C, et al. MPDL3280A (anti-PD-L1) treatment leads to clinical activity in metastatic bladder cancer. Nature. 2014; 515: 558-62.
21. Sharon E, Streicher H, Goncalves P, Chen HX. Immune checkpoint inhibitors in clinical trials. Chinese journal of cancer. 2014; 33: 434-44.

22. Huang AC, Postow MA, Orlowski RJ, Mick R, Bengsch B, Manne S, et al. $\mathrm{T}$-cell invigoration to tumour burden ratio associated with anti-PD-1 response. Nature. 2017; 545: 60-5.

23. Oken MM, Creech RH, Tormey DC, Horton J, Davis TE, McFadden ET, et al. Toxicity and response criteria of the Eastern Cooperative Oncology Group. American journal of clinical oncology. 1982; 5: 649-55.

24. Eisenhauer EA, Therasse P, Bogaerts J, Schwartz LH, Sargent D, Ford R, et al. New response evaluation criteria in solid tumours: revised RECIST guideline (version 1.1). European journal of cancer (Oxford, England : 1990). 2009; 45: 228-47.

25. Nishino M, Giobbie-Hurder A, Gargano M, Suda M, Ramaiya NH, Hodi FS. Developing a common language for tumor response to immunotherapy: immune-related response criteria using unidimensional measurements. Clinical cancer research : an official journal of the American Association for Cancer Research. 2013; 19: 3936-43.

26. Brahmer JR, Drake CG, Wollner I, Powderly JD, Picus J, Sharfman WH, et al. Phase I Study of Single-Agent Anti-Programmed Death-1 (MDX-1106) in Refractory Solid Tumors: Safety, Clinical Activity, Pharmacodynamics, and Immunologic Correlates. Journal of Clinical Oncology. 2010; 28: 3167-75.

27. Reiss KA, Forde PM, Brahmer JR. Harnessing the power of the immune system via blockade of PD-1 and PD-L1: a promising new anticancer strategy. Immunotherapy. 2014; 6: 459-75.

28. Zou W, Chen L. Inhibitory B7-family molecules in the tumour microenvironment. Nature reviews Immunology. 2008; 8: 467-77.

29. Sharma P, Wagner K, Wolchok JD, Allison JP. Novel cancer immunotherapy agents with survival benefit: recent successes and next steps. Nature reviews Cancer. 2011; 11: 805-12.

30. Chen DS, Mellman I. Oncology meets immunology: the cancer-immunity cycle. Immunity. 2013; 39: 1-10.

31. Herbst RS, Soria JC, Kowanetz M, Fine GD, Hamid O, Gordon MS, et al. Predictive correlates of response to the anti-PD-L1 antibody MPDL3280A in cancer patients. Nature. 2014; 515: 563-7.

32. Daud AI, Loo K, Pauli ML, Sanchez-Rodriguez R, Sandoval PM, Taravati $\mathrm{K}$, et al. Tumor immune profiling predicts response to anti-PD-1 therapy in human melanoma. The Journal of clinical investigation. 2016; 126: 3447-52.

33. Ribas A, Shin DS, Zaretsky J, Frederiksen J, Cornish A, Avramis E, et al. PD-1 Blockade Expands Intratumoral Memory $\mathrm{T}$ Cells. Cancer immunology research. 2016; 4: 194-203.

34. Weber JS, D'Angelo SP, Minor D, Hodi FS, Gutzmer R, Neyns B, et al. Nivolumab versus chemotherapy in patients with advanced melanoma who progressed after anti-CTLA-4 treatment (CheckMate 037): a randomised, controlled, open-label, phase 3 trial. The Lancet Oncology. 2015; 16: 375-84.

35. Taube JM, Klein A, Brahmer JR, Xu H, Pan X, Kim JH, et al. Association of PD-1, PD-1 ligands, and other features of the tumor immune microenvironment with response to anti-PD-1 therapy. Clinical cancer research : an official journal of the American Association for Cancer Research. 2014; 20: 5064-74.

36. Reck M, Rodriguez-Abreu D, Robinson AG, Hui R, Csoszi T, Fulop A, et al. Pembrolizumab versus Chemotherapy for PD-L1-Positive Non-Small-Cell Lung Cancer. The New England journal of medicine. 2016; 375: 1823-33.

37. Robert C, Long GV, Brady B, Dutriaux C, Maio M, Mortier L, et al. Nivolumab in previously untreated melanoma without BRAF mutation. The New England journal of medicine. 2015; 372: 320-30.

38. Le DT, Uram JN, Wang H, Bartlett BR, Kemberling H, Eyring AD, et al. PD-1 Blockade in Tumors with Mismatch-Repair Deficiency. The New England journal of medicine. 2015; 372: 2509-20.

39. [Internet] FDA approves first cancer treatment for any solid tumor with a specific genetic feature. https://www.fda.gov/newsevents/ newsroom/pressannouncements/ucm560167.htm

40. Blackburn SD, Shin H, Haining WN, Zou T, Workman CJ, Polley A, et al Coregulation of CD8+ T cell exhaustion by multiple inhibitory receptors during chronic viral infection. Nature immunology. 2009; 10: 29-37.

41. Twyman-Saint Victor C, Rech AJ, Maity A, Rengan R, Pauken KE, Stelekati E, et al. Radiation and dual checkpoint blockade activate non-redundant immune mechanisms in cancer. Nature. 2015; 520: 373-7.

42. Yin C, Jiang C, Liao F, Rong Y, Cai X, Guo G, et al. Initial LDH level can predict the survival benefit from bevacizumab in the first-line setting in Chinese patients with metastatic colorectal cancer. OncoTargets and therapy. 2014; 7: 1415-22

43. Agarwala SS, Keilholz U, Gilles E, Bedikian AY, Wu J, Kay R, et al. LDH correlation with survival in advanced melanoma from two large, 
randomised trials (Oblimersen GM301 and EORTC 18951). European journal of cancer (Oxford, England : 1990). 2009; 45: 1807-14.

44. Diem S, Kasenda B, Martin-Liberal J, Lee A, Chauhan D, Gore M, et al. Prognostic score for patients with advanced melanoma treated with ipilimumab. European journal of cancer (Oxford, England : 1990). 2015; 51: 2785-91

45. Kelderman S, Heemskerk B, van Tinteren H, van den Brom RR, Hospers GA, van den Eertwegh AJ, et al. Lactate dehydrogenase as a selection criterion for ipilimumab treatment in metastatic melanoma. Cancer immunology, immunotherapy : CII. 2014; 63: 449-58.

46. Diem S, Kasenda B, Spain L, Martin-Liberal J, Marconcini R, Gore M, et al. Serum lactate dehydrogenase as an early marker for outcome in patients treated with anti-PD-1 therapy in metastatic melanoma. British journal of cancer. 2016; 114: 256-61.

47. Meng X, Huang $\mathrm{Z}$, Teng F, Xing L, Yu J. Predictive biomarkers in PD-1/PD-L1 checkpoint blockade immunotherapy. Cancer treatment reviews. 2015; 41: 868-76. 